\title{
AUTOMATIC WAFFLE SLAB TECHNIQUE FOR HIGH-TECH FACTORY
}

\author{
Samuel Y.L. Yin \\ Professor, Dept. of Civil Engineering \\ National Taiwan Univ. \\ No. 1 Roosevelt Rd., Sec. 4, Taipei, Taiwan \\ Samuel@mail.ruentex.com.tw
}

\author{
H. Ping Tserng \\ Professor and Associate Chair, Dept. of Civil \\ Engineering, National Taiwan Univ. \\ No. 1 Roosevelt Rd., Sec. 4, Taipei, Taiwan \\ hptserng@ntu.edu.tw
}

\author{
W. Jue Hong \\ Ph.D. Student, Dept. of Civil Engineering National Taiwan Univ. \\ No. 1 Roosevelt Rd., Sec. 4, Taipei, Taiwan \\ D95521011@ntu.edu.tw
}

\begin{abstract}
Under the continuous compression of life cycles for products from the high-tech industry, all investors expect to recoup an enormous amount of investment within the shortest possible timeframe and raise production rapidly, so they can acquire more market opportunities and improve market share. In view of this, investors desire to shorten plant construction as much as possible.

The return air floor slab for the clean room is one of the key construction projects. This floor is a common design used in high-tech plants to control the cleanliness and humidity of the air. Concentrated openings and large thickness are the two major requirements for it. Under these two requirements, levelness and resistance to minor vibration of the floor slab must also be considered; this has caused significant difficulties in construction, where many vendors are also confronted with pressures for construction time and quality.

In order to solve the difficulties in waffle slab construction, this study has proposed a technique of precast waffle slab to meets the requirements for the high-tech industry on construction time and quality under intense market competition.
\end{abstract}

\section{KEYWORDS}

High-Tech, Precast, Waffle slab

\section{INTRODUCTION}

In recent years, the high-tech industry has taken on an important role for the economic development of Taiwan. From the design and manufacturing of semi-conductor chips to TFT-LCD, the size and complexity of plants have increased continuously. Current limits for land and production paths mean that the plane dimensions for plants are frequently limited to $200 \mathrm{~m} * 300 \mathrm{~m}$, thus the design of multifloor plants are an alternative for greater efficiency. The multi-floor plant is defined as a plant design with a production line in a vertical format and such design can enhance the efficiency of land use substantially. Since the vertical format of the plant functions motivates closer relationships between product quality and structures, many special requirements for plant construction have been derived and constitute challenges to construction technology.

The air return floor slab is a common design used in high-tech plants for controlling air cleanliness and humidity. Concentrated openings and great thickness are the two major requirements for floor slabs for the abovementioned plants. In the hightech industry with intensive market competition, 
time happens to be one of the key elements relating to product success, where many vendors have also confronted distinct pressures for shortening construction time. The quality, construction time and cost are often the demands from a client on construction works, but these three demands often influence different results under for the difficult and complex work.

The traditional technique for high-tech plant construction face many problems during construction and the precast floor slab is one of the most effective solutions; this study will compare the differences between the two methods practically, and follows by analyzing the production and work with the precast system further.

\section{PROBLEM STATEMENT}

Products in the high-tech industry change at a rapid rate and with a continuous compression of life cycles. Investors wish to recoup an enormous amount of investment within the shortest possible time and raise production rapidly, so they can acquire greater market opportunities and improve their market share. In view of this, the construction of a high-tech plant must comply with the characteristics of the industry. For construction of such a high-tech plant, the quality of the return air floor slab in the clean room is very important since such slab is constructed in a large area; as for the most important requirements on waffle slabs, namely the "resistance to minor vibration" and "levelness of the floor slab", traditional construction often faces challenges on quality and construction time and the main problems are as follows:

- The work quality and precision are not easy to control

- Labor safety

- It is difficult to shorten construction time

In order to solve the above-mentioned problems generated from traditional construction, this study proposes to apply a thorough precast technique from preliminary planning to production of precast components.

\section{CONSTRUCTION TECHNIQUE FOR WAFFLE SLAB}

\subsection{Traditional Technique}

Since high-tech plants occupy a very large area, each floor has a large span and the length/width of the waffle slab may reach $100 \mathrm{~m}$. In the traditional technique, the materials are stored onsite first and supports are established for worker convenience. After completion of the supports and formwork assembly, workers can start cutting and tying the reinforcement, which is followed by inserting the opening steel cylinder into the reinforcement and the structure is ready for grouting. After curing, the formwork is removed and the waffle slab is completed.

However, traditional construction of waffle slabs will cause an excessive waste of manpower, machinery and materials, in addition to various wastes that occur at each construction step, there are still many problems such as occupancy of site space, disordered environment, mold damage, theft risk, labour safety problem, formwork deformation, high dependence on skilled labourers and long time for waiting the EPOXY evaporation of moisture in the concrete which need to be improved for the cast-in-place technique.

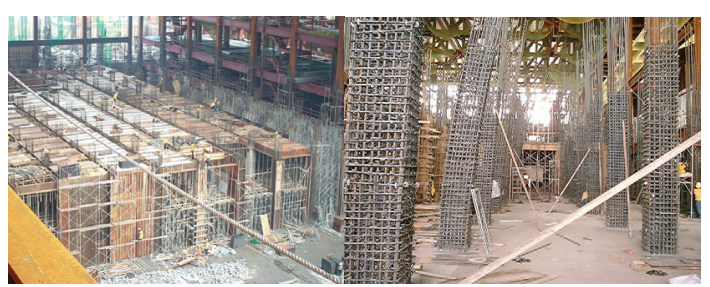

Figure 1 Traditional Technique Problems

\subsection{Precast Technique}

Before production of the precast waffle slab at the precast plant, material must be planned first, where the production components are then modulated. After that, the precast components are produced in the plant and the finished products are delivered onsite after completion. Hoist machinery is used to hoist the waffle slabs to the construction floor for assembly. Altitude positioning is then carried out after hoisting, which is followed by concrete pouring for connection. 
The each step solves the problems in traditional technique as follow:

- Precise construction and modulation: It solves the site space occupied by materials, disordered site environment, damaged steel cylinders, risk of material theft, waste from material consumption and repetitive works

- $\quad$ Production of precast components: It solves the obstruction of construction path, labor safety, deformation of formwork, high dependence on skilled laborers, height difference generated from steel cylinder, displacement or deformation of steel cylinder, interior contamination of steel cylinder, displacement or deformation of steel cylinder and adverse workability.

- Hoisting of machinery: It solves the bursting formwork and supports during grouting, curing period for concrete is too long and failure of compressing construction time for work on single floor.

- Altitude positioning: It solves the uneven floor surface.

- Pouring concrete for connection: It solves the construction area is too large and cannot be completed at once.

For precast technique, since the slab units are produced in advance, the precision and levelness are easier to control during production. With the measurement of altitude positioning during onsite assembly, the altitude difference between the slabs can be reduced to ensure compliance with the design requirements. In addition, the strength of the precast slabs are sufficient to sustain their self weight and work load, thus no work platform or supports need to be set up, which improves the construction path effectively. Finally, since the precast technique removes traditional site operation with more difficulty away from the critical path, the site is only left with hoists; thus multiple floors can be constructed at the same time and the construction time can be reduced effectively.

\section{PRODUCTION OF PRECAST WAFFLE SLAB}

\subsection{Planning Production Procedures for Precast Waffle Slab}

In order to prevent waste from traditional construction and the abovementioned problems, the path of material use and supply must be planned before manufacturing the precast waffle slabs. Moreover, modulated production of waffle slabs shall be considered to comply with the limits of the load bearing hoist machinery, which reduces unnecessary waste, as well as increasing construction efficiency and benefits.

For material use planning, problems such as material waste, secondary fabrication onsite and failure of timely material supply occur most easily with traditional cast-in-place construction. In the process of traditional cast-in-place construction, obstruction of the construction path is the greatest problem because the traditional cast-in-place construction requires enormous amount of supports and formworks. This causes limitations to the construction paths of personnel, machinery and material.

In order to prevent these problems during the production of precast waffle slabs, the following principles can be applied:

- Make the size of the material consistent with the specification on the design drawing upon entry to the plant to reduce resources and manpower wasted during production of reinforcement, as well as secondary fabrication or cutting.

- Order materials in batches according to the amount of work sequence planned. Such amount must not be excessive or ordered all at once, otherwise, the work space will be occupied for a long term, which affects the construction path and increases expenses for material arrangement.

- $\quad$ The entry of material shall not be too early or late, and must be delivered on time according to the site regulations

- The material (components) piled within the fixed storage area shall comply with the operation sequence of the site operation, 
where storage is executed with coding at fixed space for ease of searching.

- Deliver the material to the assigned area for storage and fabrication with transportation resources planned in advance.

- During production, plan the material delivery, quantity, application time and application method for construction tools.

- The construction site is planned with a fixed path for material delivery (including horizontal delivery and vertical hoisting).

\subsection{Production Procedures for Reinforcement Cage}

Before production of precast waffle slab, the reinforcement cage must be planned and produced first. The procedures are as follows:

- Planning for the reinforcement material

- Fabrication of reinforcement and hoops

- Reinforcement assembly and placement in $\mathrm{x}$ and $\mathrm{y}$ axis.

- Tying reinforcement cage.

- Assembly completed.

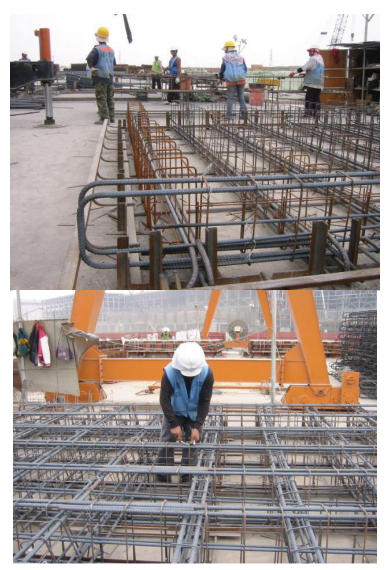

Figure 2 Reinforcement assembly and placement in $x$ and $y$ axis.

\subsection{Production Procedures for Precast Waffle Slab}

This study has proposed two types of production for precast waffle slab, namely the semi-precast waffle slab and fully-precast waffle slab. Since each floor of a high-tech plant has different requirements on loading capacity, such capacity shall be designed according to the layout of the facilities on each floor. Floors with greater load capacities shall use thicker floor slabs. However, there is a load limitation for precast floor slab when hoisted with machinery, thus thicker slabs will not be able to be hoisted with machinery. In view of this, the study has proposed the semiprecast waffle slab for floors with heavier loading and greater design thickness, whilst fully-precast waffle slabs are adopted for floors with lighter loading and thinner design thickness.

In a high-tech plant, if the floor load is great and a thicker floor slab must be used, a fully precast slab might be too heavy for the machine to hoist under consideration of the loading limitation of the machine, thus the construction of a semi-precast waffle slab is adopted. The construction principle is to adjust the levelness and dimensions of the steel mold for the precast waffle slab first, which is followed by cleaning, placing a base cover over the opening of the mold, hoisting the reinforcement cage, placing the opening mold, pouring and curing the concrete to complete the semi-waffle slab, where the slab is hoisted to the construction floor for completion of pouring.

If the floor loading is not large, a floor slab with a smaller designed thickness can be adopted. During precast production, since the floor slab is thinner and lighter, a fully precast technique can be adopted within the load limitation of the hoisting machine. The construction principle is to adjust levelness and dimension of the steel molds for precast waffle slabs first, which is followed by placing the steel cylinder base cover, hoisting the reinforcement cage, placing the steel cylinder, pouring and curing the concrete, and then coating EPOXY on the surface for completion.

\subsection{Hoist the Precast Waffle Slab}

During construction of a high-tech plant, steel girders can be installed on the columns after completion of the foundation and column erection. For precast columns between the 1st and 2nd floor, the space between the columns allows entry of a wheel crane, thus slabs can be hoisted with wheel crane accordingly. For floors above the 2nd floor, wheel cranes cannot be used since the girders will obstruct the boom extension. In view of this, 
waffle slabs above the 2nd floor will be installed with a overhead crane. In traditional construction, the floor slabs only allow construction on a single floor; with a precast hoist however, the wheel crane and overhead crane can work at the same time, thus simultaneous slab installation can be executed on each floor. In this way, construction time compression problems stemming from construction on only single floor with traditional construction can be improved upon significantly.
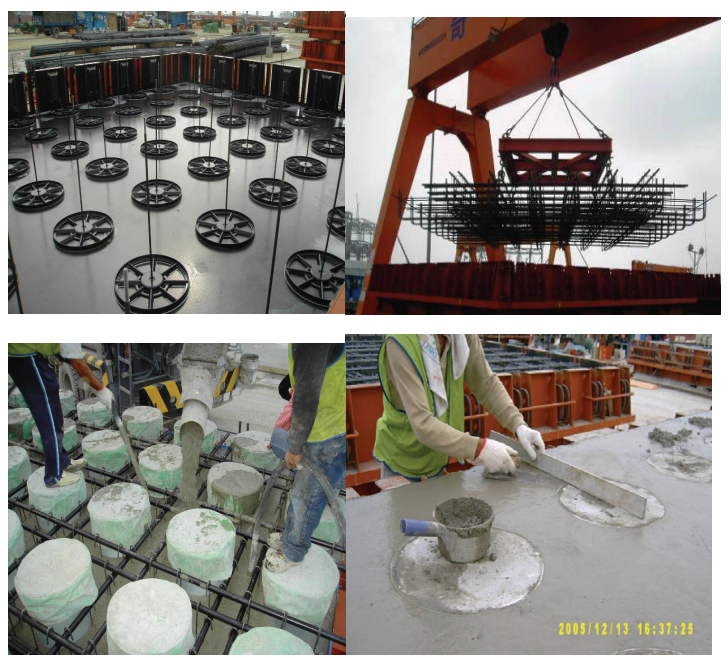

Figure 3 Precast Waffle Slab Production
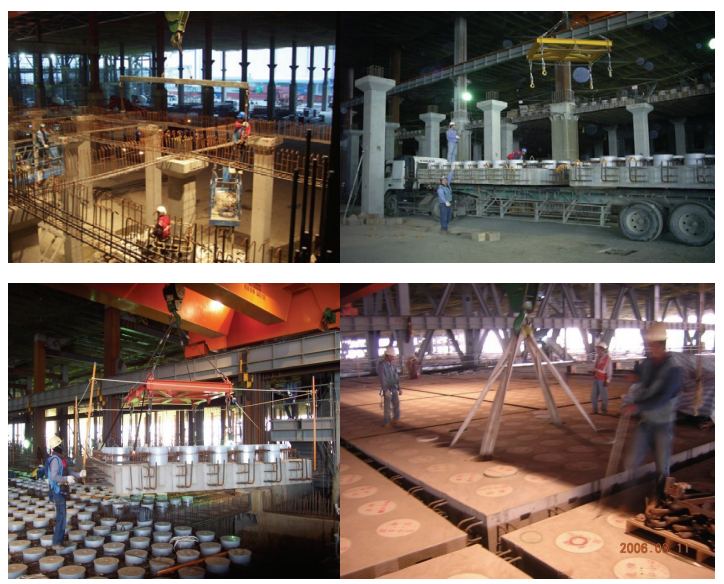

Figure 4 Hoisting the Precast Waffle Slab

\section{BENEFIT EVALUATION}

When waffle slabs are made using the precast technique, they can be divided into fully precast and semi-precast slabs. The following content provides a comparison between the precast technique and the traditional cast-in-place construction:

- Construction time: From the table below, it can be seen that the fully precast waffle slab onsite is only left with hoisting operations and it can be executed on multiple floors simultaneously; this provides the fastest construction speed of $1.5 \mathrm{span} /$ day. For semiprecast waffle slab, since concrete pouring and curing are still required onsite, the construction speed can only achieve 1 span/day. For traditional construction, since all operation is carried out onsite, the construction speed is the slowest at only 0.5 span/day. Therefore, the precast technique does provide a significant effect on the compression of construction time.

- Safety cost: Since the waffle slab with precast technique is produced in precast plant almost completely, the site is only left with hoisting operations, thus massive scaffolds and formwork supports can be reduced. Moreover, the chances of elevated work and debris generated from construction are also reduced. Since the site does not require storage for large amount of materials, it provides great assistance to maintaining the environment. Therefore, the security cost of the precast technique is only $1 / 5$ of the traditional technique.

- Manpower demand: From production of the reinforcement cage to precasting the waffle slab, the precast technique mostly uses molds to assist in production. Since the materials used are well planned, the hoisting operation onsite only requires machinery and a few skilled laborers to complete the work. Taking a fully precast waffle slab as example, the work takes only 17 workers/day; the semiprecast needs 30 workers/day since concrete pouring is still required onsite, whilst the traditional cast-in-place technique requires the largest number of skilled laborers at 105 workers/day, because all operations are completed onsite. Given the deficiency of skilled laborers nowadays, the precast 
technique helps solve this problem efficiently.

- Reinforcement consumption: Since the precast technique for manufacturing reinforcement cages is planned for the reinforcement use in advance, the materials are consistent with the dimensions specified on the design drawings upon entry to the plant, which reduces resource wasted from secondary fabrication or cutting during production of reinforcement. Compared to traditional cast-in-place technique, the precast technique provides a lower consumption of reinforcement.

- Unit rate: Since the fully precast technique is only left with hoisting operations onsite, its unit rate can achieve 9(slabs/day)*30(M2/slab). The semi-precast method still requires concrete pouring and curing onsite, thus the unit rate is lower than the fully precast technique, but can still achieve 6(slabs/day)*30(M2/slab). For the traditional cast-in-place technique, since all operations are executed onsite, the unit rate is relatively lower and only achieves 3(slabs/day)*30(M2/slab).

- Workability: The precast technique and the traditional technique each has its own advantages and disadvantages. The precast technique improves problems faced under traditional technique significantly, but requires a longer time for preliminary planning; if design variation occurs, tremendous influences will be caused to the precast production. Although there are still many construction problems worth discussing for the traditional technique, it required a shorter time for preliminary planning and is therefore more flexible against variation.

\section{CONCLUSIONS}

Facing demands of construction speed for hightech plants, this study proposes the precast waffle slab technique to reduce unnecessary waste during production, so modulated operation can standardize the basic conditions of products during production, which provides stable and consistent quality. The operations of reinforcement cage prefabrication and precast waffle slabs not only reduces site works, but also implements critical operations in advance and speeds up the work progress. To improve the hoisting methods, different hoist machines are used to simultaneously hoist fully and semi-precast waffle slab, which further accelerates the construction progress. With variation in automated production and hoisting methods, the precast waffle slabs are not only capable of improving upon the inconveniences of traditional construction significantly, but also achieve the requirements of a shorter construction schedule for high-tech plants.

\section{REFERENCES}

[1] Wood, S., Wright, J., and Moehle, J. (1987). The 1985 Chile earthquake, observations on earthquake-resistant construction in Vina del Mar. Civil Engineering Studies, Structural Research Series No. 532, Univ. of Illinois, Urbana, Ill.

[2] Wyllie, L. A, Jr., and Filson, J. R.(1989). "Armenia earthquake reconnaissance report." Earthquake Spectra Publication No. 89.01, Special Supplement.

[3] Hasan Husnu Korkmaz, Tugrul Tankut(2005). "Performance of a precast concrete beam-tobeam connection subject to reversed cyclic loading. " Engineering Structures 27 (2005) 1392-1407

[4] Shahid Nasir, Supratic Gupta, Hidetaka Umehara, Ikuo Hirasawa (2001). An efficient method for the construction of bridge piers, Engineering Structures 23 (2001) 1142-1151

[5] Tatsuya Wakisaka, Noriyuki Furuya, Yasuo Inoue, Takashi Shiokawa (2000). Automated construction system for high-rise reinforced concrete buildings. Automation in Construction 9_2000.229-250

[6] Taehoon Hong, Makarand Hastak (2006) Simulation study on construction process of FRP bridge deck panels, Automation in Construction, 16 (5), 620-631.

[7] Tony Holden; Jose Restrepo; and John B. Mander (2003). Seismic Performance of Precast Reinforced and Prestressed Concrete Walls, JOURNAL OF STRUCTURAL ENGINEERING, 129(3), 286-296 